Preface

\title{
Hemostatic and Nonhemostatic Effects of Heparan Sulfate Proteoglycans
}

\author{
Yona Nadir, MD, $\mathrm{PhD}^{1}$ Ton Lisman, $\mathrm{PhD}^{2}$ \\ 1 Thrombosis and Hemostasis Unit, Rambam Health Care Campus, \\ The Ruth and Bruce Rappaport Faculty of Medicine, Technion, \\ Haifa, Israel \\ 2 Department of Surgery, Surgical Research Laboratory, University \\ Medical Centre Groningen, University of Groningen, Groningen, \\ The Netherlands
}

Semin Thromb Hemost 2021;47:238-239.

Heparan sulfate proteoglycans (HSPGs) are composed of negatively charged heparan sulfate (HS) chains linked to a core protein. HS chains have an ancient evolutionary history, and are highly conserved. Virtually every cell type in metazoan (multicellular animals) organisms produces HS. The chains are synthesized by a highly ordered sequence of enzymatic events in the Golgi apparatus and are present on cell surface membranes, membranes of intracellular organelles, basement membranes, and in the extracellular matrix. These complex polysaccharides serve as low-affinity receptors to numerous proteins that contain a heparin-binding domain. Modulation of the HS chains may potentially affect cell surface interactions with numerous molecules, cells, and microparticles. ${ }^{1}$ As HSPGs are important gatekeepers at the cell surface, they are involved in ample biological processes including hemostasis. In the present issue of Seminars in Thrombosis and Hemostasis, we introduce several fields where a significant role of HSPGs has been established, making them an important mechanism linking hemostasis, inflammation, angiogenesis, and cancer. Research in the field of HS chains is lagging behind because of the lack of advanced laboratory assays. While the protein part in the HSPGs complex (e.g., syndecan) can be easily evaluated using an antibody interacting with the protein, commercially available assays to assess the sugar chains of HS are sparse.

\section{HSPGs in Human Pathologies}

In the present issue, Vlodavsky at al discuss the effect of the heparanase protein on the HS chains, and outline how the modification of HS chains acts in processes such as inflammation, angiogenesis, and tumor growth. ${ }^{2}$ Heparanase is the only enzyme in vertebrates known to degrade HS chains, and thus the only known modulator of HS activity. Heparanase is able to degrade HS chains in only one specific site, which is the antithrombin-binding pentasaccharide sequence. In addition, heparanase induces release of the HSPG syndecan from cell

\footnotetext{
Address for correspondence Issue Theme Hemostatic and Yona Nadir, MD, PhD, Thrombosis Nonhemostatic Effects of and Hemostasis Unit, Rambam Heparan Sulfate Proteoglycans; Health Care Campus, Haifa, Israel Guest Editors: Yona Nadir, MD, (e-mail: y_nadir@rambam.health. PhD and Ton Lisman, PhD. gov.il).
}

surfaces. Intervening in heparanase activity is a potential way to affect HS chains length and level, and could be beneficial in diseases in which inflammation or angiogenesis are relevant as well as in cancer. Next, Nadir discusses the effect of heparanase and HS chains on the hemostatic system. ${ }^{3}$ Heparanase has been shown to directly affect the coagulation system by enhancing tissue factor activity. In addition, the interaction of antithrombin and tissue factor pathway inhibitor with HS chains is a key mechanism of thrombosis prevention. Degradation of HS chains by heparanase at the endothelial cell surface and release of these anticoagulant proteins, may tip the balance toward a procoagulant milieu. The next contribution by Hiebert demonstrates that in diabetes, modified HSPGs in the endothelium and extracellular matrix contribute to nephropathy, cardiovascular disease, and retinopathy present in diabetes. ${ }^{4}$ The interaction between high glucose levels and heparanase upregulation, resulting in modulation of HS chains in cells, is described and the role of heparanase in enhancing atherosclerosis and hampering lipid metabolism is discussed. Oshima et al then analyze the influence of endothelial HSPGs shedding that occurs during sepsis in terms of endothelial cell function and show that local and systemic vascular dysfunction is in part mediated by HSPGs. ${ }^{5}$ Potential therapeutic strategies to improve vascular function in patients with sepsis are outlined. Another interesting aspect touched upon in this issue is the involvement of HSPGs in viral infection as depicted by Koganti et al. ${ }^{6}$ Numerous viruses often interact with the HSPGs on endothelial or epithelial cells at the time of attachment. Thus, the cell surface HSPGs are used as receptors for viral entry into cells. Identification of the mechanisms underlying cell surface interactions between viruses and cells via HS may broaden our understanding of other cell-cell and cell-microparticle interactions. Using competitive inhibitors of HS, such as heparin molecules, early during infection could lead to a significant decrease in viral infectivity.

(c) 2021. Thieme. All rights reserved. Thieme Medical Publishers, Inc., 333 Seventh Avenue, 18th Floor, New York, NY 10001, USA
DOI https://doi.org/ 10.1055/s-0041-1724119. ISSN 0094-6176. 
Table 1 Heparan sulfate proteoglycans (HSPGs) are involved in numerous physiological and pathological processes and may be utilized as biomarkers and therapy targets

\begin{tabular}{|l|l|}
\hline HSPGs are present: & $\begin{array}{l}\text { On the cell surface } \\
\text { On the intracellular organelle surface membranes (e.g., nucleus) } \\
\text { In the basement membrane and extracellular matrix }\end{array}$ \\
\hline HSPGs are: & $\begin{array}{l}\text { Endothelial anticoagulants } \\
\text { Low affinity receptors to numerous proteins } \\
\text { Effectors of cell-cell interactions, cell-extracellular microvesicles interactions, } \\
\text { and cell-virus interactions }\end{array}$ \\
\hline HSPGs are involved in: & $\begin{array}{l}\text { Hemostasis } \\
\text { Diabetic complications in the kidney, heart, and eye } \\
\text { Sepsis, inflammation } \\
\text { Viral infections } \\
\text { Neurogenesis }\end{array}$ \\
\hline $\begin{array}{l}\text { Posttranslation, heparan } \\
\text { sulfate chains are modulated } \\
\text { by a single enzyme named heparanase } \\
\text { Heparanase affects: }\end{array}$ & $\begin{array}{l}\text { Hemostasis } \\
\text { Inflammation } \\
\text { Angiogenesis } \\
\text { Cancer growth }\end{array}$ \\
\hline HSPGs applications: & $\begin{array}{l}\text { Biomarkers: diagnostic and prognostic } \\
\text { Targets to therapy by inhibition of: heparan sulfate chains, HSPGs, heparanase }\end{array}$ \\
\hline
\end{tabular}

\section{HSPGs as Biomarkers and Treatment Targets}

Lepedda et al then introduce the diagnostic and prognostic value of circulating HSPGs. ${ }^{7}$ The level of HSPG released into the bloodstream is demonstrated to correlate with disease severity in various pathologies such as cardiovascular disease, cancer, sepsis, and trauma. Whether the level of HSPG shed into plasma could be used as a prognostic biomarker in health and disease needs to be further investigated. HSPGs are established as key regulators and mediators of neural development. Peall et al thus present an overview on the current knowledge in three-dimensional human neural stem cell models, discussing their application in exploring HSPGs and the neural extracellular niche. ${ }^{8}$ Better understanding of the role of HSPGs in neurologic pathologies could advance therapeutic approaches. Moreover, these models might be applicable to HS research on other stem cell types and their extracellular niche. Gerlza et al then provide insights into the development of new drug compositions and methods targeting HSPGs and heparanase in cancer and inflammatory diseases. ${ }^{9}$ These studies are ongoing and will hopefully pave the way to novel strategies in cancer and rheumatic treatment.

\section{HSPGs as a Link between Hemostasis, Cancer, and Inflammation}

-Table 1 summarizes the main knowledge on HSPGs presented in this issue. The involvement of HSPGs in hemostasis, cancer, angiogenesis, and inflammation may imply that these molecules, located on the cell surface, could be a vital link in various physiological and pathological processes. Development of accurate and efficient measurement tools to evaluate HS chain length, charge, and level would contribute to the elucidation of the HS role as a porter at membrane surfaces.

Conflict of Interest

None declared.

\section{References}

1 Esko JD, Selleck SB. Order out of chaos: assembly of ligand binding sites in heparan sulfate. Annu Rev Biochem 2002;71:435-471

2 Vlodavsky I, Barash U, Nguyen HM, Yang S-M, Ilan N. Biology of the heparanase-heparan sulfate axis an its role in disease pathogenesis. Semin Thromb Hemost 2021;47(03):240-253

3 Nadir Y. Effect of heparanase and heparan sulfate chains in hemostasis. Semin Thromb Hemost 2021;47(03):254-260

4 Hiebert LM. Heparan sulfate proteoglycans in diabetes. Semin Thromb Hemost 2021;47(03):261-273

5 Oshima K, King SI, McMurtry SA, Schmidt EP. Endothelial heparan sulfate proteoglycans in sepsis: the role of the glycocalyx. Semin Thromb Hemost 2021;47(03):274-282

6 Koganti R, Memon A, Shukla D. Emerging roles of heparan sulfate proteoglycans in viral pathogenesis. Semin Thromb Hemost 2021; 47(03):283-294

7 Lepedda AJ, Nieddu G, Piperigkou Z, Kyriakopoulou K, Karamanos N, Formato M. Circulating heparan sulfate proteoglycans as biomarkers in health and disease. Semin Thromb Hemost 2021; 47(03):295-307

8 Peall IW, Okolicsanyi RK, Griffiths LR, Haupt LM. 3D human neural stem cell models to mimic heparan sulfate proteoglycans (HSPGs) and the neural niche. Semin Thromb Hemost 2021;47(03): 308-315

9 Gerlza T, Trojacher C, Kitic N, Adage T, Kungl AJ. Development of molecules antagonizing heparan sulfate proteoglycans (HSPGs). Semin Thromb Hemost 2021;47(03):316-332 